\title{
Water Penetration of Concrete made with Coarse Aggregates from Demolishing Waste
}

\author{
Muhammad Fahad Koondhar \\ Department of Civil Engineering \\ Quaid-e Awam University of Engineering, \\ Science \& Technology \\ Nawabshah, Pakistan \\ kingblackzero@gmail.com
}

\author{
Bashir Ahmed Memon \\ Department of Civil Engineering \\ Quaid-e-Awam University of Engineering, \\ Science \& Technology \\ Nawabshah, Pakistan \\ bashir_m@hotmail.com
}

\author{
Mahboob Oad \\ Department of Civil Engineering \\ Quaid-e-Awam University of \\ Engineering, Science \& Technology \\ Nawabshah, Pakistan \\ engrmahboob04@gmail.com
}

\author{
Faraz Ahmed Chandio \\ Department of Civil Engineering \\ Quaid-e-Awam University of \\ Engineering, Science \& Technology \\ Nawabshah, Pakistan \\ farazahmedchandio04@gmail.com
}

\author{
Sheerz Ahmed Chandio \\ Department of Civil Engineering \\ Quaid-e-Awam University of \\ Engineering, Science \& Technology \\ Nawabshah, Pakistan \\ sheeraz.ahmed030@gmail.com
}

\begin{abstract}
The results of laboratory investigations on water penetration in concrete made with coarse aggregates from demolishing waste are presented in this paper. Seven batches of standard size concrete cubes were cast with recycled aggregates from demolished concrete replacing coarse aggregates in percentages from $0 \%$ to $60 \%$. The compressive strength of the samples was evaluated by non-destructive testing with the use of the Schimidz hammer. It was found that the strength reduces with an increase in recycled aggregate percentage. The maximum loss of strength due to the induction of recycled aggregates was $32 \%$ in the batch with $60 \%$ recycled aggregates. All samples were subject to constant water pressure of 5 bars for 72 hours. From the obtained results it was shown that the water penetration depth increases with increase in recycled aggregates rate. With $10 \%$ and $20 \%$ replacement the samples allowed less water to penetrate than conventional concrete samples, but $76 \%$ more penetration depth was recorded in samples with $60 \%$ replacement. Strength and water penetration results from dosages up to $20 \%$ show that the durability of the produced concrete allows it to be used in structural members with consideration of strength reduction in the design process. However, more water penetration with higher dosages of recycled aggregates needs proper care in design and usage of the concrete particularly for locations where concrete is exposed to water pressure.
\end{abstract}

Keywords-green concrete; recycled aggregates; demolishing waste; permeability; water penetration

\section{INTRODUCTION}

Green concrete utilizes alternative concrete ingredients often involving waste generated from primary processes. Waste generated due to demolishing of old structures poses a serious problem. This waste to some extent is utilized as filling material and the remaining goes to landfills. In agriculture dependent countries like Pakistan, the land near the cities is agricultural. Thus, dumping the waste in landfills will lead to adverse effects to the land and the environment. One of the options to minimize waste is by using it in new concrete as coarse aggregates. The green concrete developed by using the demolishing waste will not only reduce the waste amount to some extent, but will also reduce the negative impacts of quarrying for coarse aggregate production. However, the developed concrete should be checked for its properties with respect to conventional concrete to develop confidence in its use. Research on the use of demolishing concrete as coarse aggregates is active the last few decades. In this regard, authors in $[1,2]$ published review articles on the recent developments on the use of waste in fresh concrete with reference to recycling of aggregates, issues associated with the processes and its impact on the final strength of concrete.

Among various concrete properties, permeability is one of the most important. It controls the water infiltration in concrete, thus preventing the rusting of steel and strengthening the bond strength between steel and concrete. Also, it is the property which allows the flow of water through the concrete body if that is required, as in the case of thirsty concrete. In a research investigation, while checking the permeability of pavement concrete made with recycled aggregates and dolomite and marble waste, author in [3] observed the good permeability of the proposed material but noticed the decreased strength of recycled aggregate concrete in comparison with conventional concrete and concrete made with dolomite and marble waste. In another experimental study of the properties of pervious concrete, authors in [4] suggested 0.35 as water-binder ratio with enough strength of concrete to be used in sidewalks and civic paving projects. Permeability characteristics of fiber reinforced high performance concrete and fiber reinforced 
concrete made with recycled aggregates as coarse and fine aggregates have been studied in $[5,6]$. Based on the permeability results of the proposed concrete, the authors concluded that recycled aggregates partially replacing fine and coarse aggregates give almost similar properties as conventional concrete. The test results of concrete made with various alternative materials [7-17] regarding suitability [18], strength and durability [19], root cause of waste generation [20], sustained loading for 9 and 12 months [21, 22], fire resistance at $1000 \mathrm{C}$ for 18 and 24 hours $[23,24]$ show the promising effects of recycled aggregates as replacement materials suitable to be used in new concrete. Demolishing waste has also been tested as replacement of fine aggregates. To this end, authors in [25] replaced fine aggregates with demolishing waste by $10 \%, 30 \%, 50 \%$ and $100 \%$. Laboratory tests of various properties of concrete showed results comparable to the conventional concrete's. Recycled aggregates with supplementary cementitious materials have been used in [26] to check the permeability of concrete at laboratory scale. The results revealed good resistance to water penetration in the proposed concrete. Authors in [27] performed laboratory investigations on six different concrete mixes with recycled aggregates in order to study the permeability characteristics under desiccation conditions. The study considered fresh concrete in ventilated tunnel and showed a reduction in the bleeding of the concrete with low water cement ratio. Liquid penetration depth and strength of concretes modified with polymer admixtures under the effect of crude-oil products was studied in [28].

Although a few attempts have been made to study the water penetration in concrete with demolishing waste in different conditions with and without other ingredients, the scattering of the results shows that more work is needed to develop the confidence in the use of this material. Therefore, this experimental study aims to evaluate the permeability of concrete made with coarse aggregates from demolishing waste at different percentages. It is hoped that the outcome will set a landmark for scholars and guidelines for relevant industry research.

\section{MATERIALS AND TESTING}

\section{A. Concrete Ingidients}

Demolished concrete was obtained from a 60 year old demolished reinforced concrete structure. The transformation of the material in coarse aggregates of maximum $25 \mathrm{~mm}$ size was done manually by hammering. The obtained material was then sorted for debris and other unlikely materials followed by washing and drying in the laboratory. Same size conventional coarse aggregates were obtained from the local market. Sorting and washing of these aggregates were also done in similar fashion. These materials are shown in Figure 1. To prepare the proposed specimens, hill sand confirming the ASTM requirements was used as fine aggregates. Ordinary Portland cement under the brand name Pakland along with hill sand, obtained from the local market was used.

\section{B. Specimen Preparation}

A total of seven concrete mixes were made. Among these mixes, one batch was prepared with only conventional coarse aggregates, whereas in the rest six batches, conventional coarse aggregates were replaced with recycled aggregates from demolished concrete with percentages from $10 \%$ to $60 \%$. In each batch, four cubical specimens of standard size were prepared using 1:2:4 mix and 0.5 water to cement ratio. Both parameters were selected due to their frequent occurrence in the construction industry. Water obtained from the city water supply line having $\mathrm{pH}$ value equal to 6.9 was used for the preparation of the mixes. Table I shows the details of the materials used in each batch. All the ingredients were mixed in a concrete mixer.

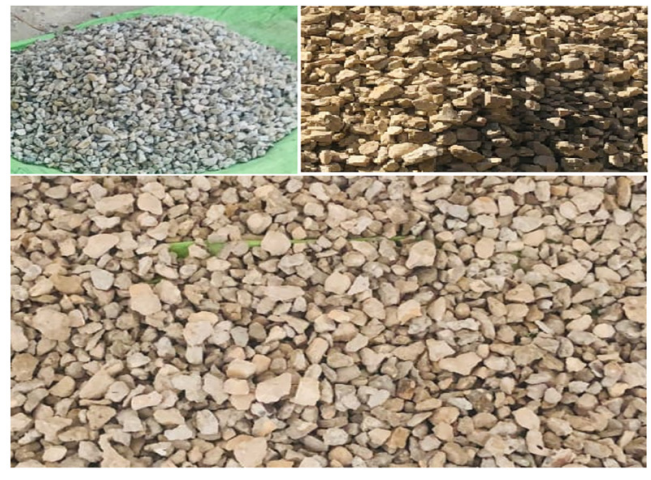

Fig. 1. Conventional and recycled aggregates.

TABLE I. MATERIALS

\begin{tabular}{|c|c|c|c|c|c|c|c|}
\hline No & $\mathbf{1}$ & $\mathbf{2}$ & $\mathbf{3}$ & $\mathbf{4}$ & $\mathbf{5}$ & $\mathbf{6}$ & $\mathbf{7}$ \\
\hline Batch & $\mathrm{B} 1$ & $\mathrm{~B} 2$ & $\mathrm{~B} 3$ & $\mathrm{~B} 4$ & $\mathrm{~B} 5$ & $\mathrm{~B} 6$ & B7 \\
\hline RCA (\%) & 0 & 10 & 20 & 30 & 40 & 50 & 60 \\
\hline No. of cubes & 4 & 4 & 4 & 4 & 4 & 4 & 4 \\
\hline Cement (kg) & 6 & 6 & 6 & 6 & 6 & 6 & 6 \\
\hline Fine aggr. (kg) & 12 & 12 & 12 & 12 & 12 & 12 & 12 \\
\hline Coarse aggr. (kg) & 24.0 & 21.6 & 19.2 & 16.8 & 14.4 & 12.0 & 9.6 \\
\hline RCA (kg) & 0.0 & 2.4 & 4.8 & 7.2 & 9.6 & 12.0 & 14.4 \\
\hline Water (kg) & 3 & 3 & 3 & 3 & 3 & 3 & 3 \\
\hline
\end{tabular}

Cube specimens were prepared by first oiling the inner surface of moulds, followed by filling with concrete in layers. A table vibrator was used to compact the concrete in the moulds. The specimens were de-moulded after $24 \mathrm{~h}$ and left in the laboratory to air dry for next $24 \mathrm{~h}$. Curing of the specimens was done by fully immersing them in potable water for 28 days.

\section{Specimen Testing}

After the curing period, the specimens were taken out of the water and were allowed to air dry for $24 \mathrm{~h}$. All the specimens were then tested for compressive strength with the NonDestructive Testing (NDT) of the Schimidz hammer. The obtained results are listed in Table II. After the strength testing, the specimens were tested for water penetration in accordance with the procedure defined by ASTM C642 for the purpose [29] and were mounted on a water penetration test machine (Figure 2). The available machine tests six specimens at a time, therefore, the specimens were tested in turn. The specimens were mounted on the machine followed by filling of the cylinders with water. The water pressure was raised and kept equal to $5 \mathrm{bars}\left(5 \mathrm{~kg} / \mathrm{cm}^{2}\right)$ for $72 \mathrm{~h}$. After the completion of this period, the specimens were un-mounted, and the surface water 
was wiped off. The specimens were then split in to two parts in a universal testing machine (Figure 3 ). The internal structure of the specimens was found compacted without any visible voids. The saturated surface was marked and the depth of water at six different locations was recorded. The obtained results are listed in Table III.
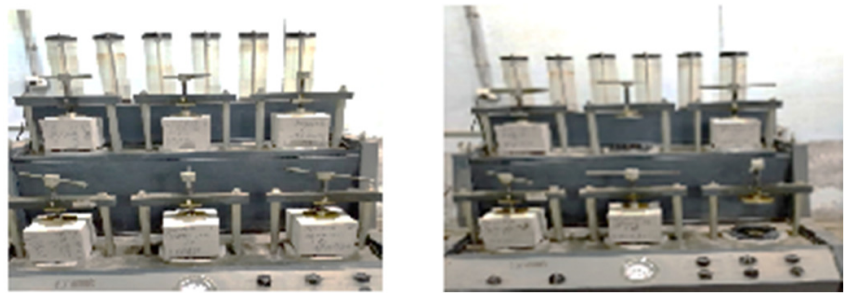

Fig. 2. Water penetration test.
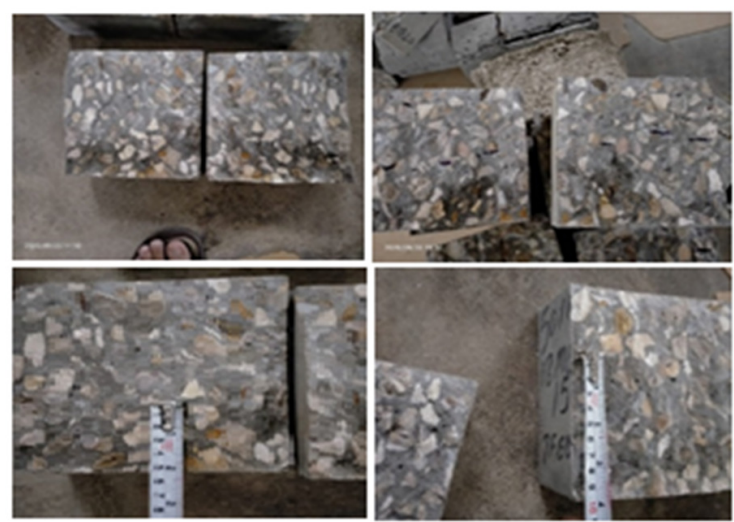

Fig. 3. Specimens after water penetration

TABLE II. NDT COMPRESSIVE STRENGTH RESULTS

\begin{tabular}{|c|c|c|c|}
\hline Batch & Sample No & RCA (\%) & Compressive strength (psi) \\
\hline \multirow{4}{*}{ B1 } & 1 & \multirow{4}{*}{0} & 2892 \\
\hline & 2 & & 2953 \\
\hline & 3 & & 2881 \\
\hline & 4 & & 2853 \\
\hline \multirow{4}{*}{ B2 } & 1 & \multirow{4}{*}{10} & 2567 \\
\hline & 2 & & 2681 \\
\hline & 3 & & 2645 \\
\hline & 4 & & 2581 \\
\hline \multirow{4}{*}{ B3 } & 1 & \multirow{4}{*}{20} & 2281 \\
\hline & 2 & & 2181 \\
\hline & 3 & & 2367 \\
\hline & 4 & & 2367 \\
\hline \multirow{4}{*}{ B4 } & 1 & \multirow{4}{*}{30} & 2119 \\
\hline & 2 & & 2260 \\
\hline & 3 & & 2119 \\
\hline & 4 & & 2253 \\
\hline \multirow{4}{*}{ B5 } & 1 & \multirow{4}{*}{40} & 2053 \\
\hline & 2 & & 2045 \\
\hline & 3 & & 2053 \\
\hline & 4 & & 2181 \\
\hline \multirow{4}{*}{ B6 } & 1 & \multirow{4}{*}{50} & 1912 \\
\hline & 2 & & 1918 \\
\hline & 3 & & 1881 \\
\hline & 4 & & 1912 \\
\hline \multirow{4}{*}{ B7 } & 1 & \multirow{4}{*}{60} & 1753 \\
\hline & 2 & & 1767 \\
\hline & 3 & & 1667 \\
\hline & 4 & & 1781 \\
\hline
\end{tabular}

\section{RESULTS AND DISCUSSION}

The compressive strength results of all specimens within a batch are averaged and plotted in Figure 4. The decreasing trend with increase in percentage of recycled aggregates can be observed. Maximum loss of strength is recorded with the highest replacement level. With $10 \%$ and $20 \%$ replacement levels, the loss of strength is about $10 \%$ and $23 \%$ respectively. The water penetration results for all samples of all batches are averaged in Table IV. It may be observed that the maximum and minimum depth of water penetration in conventional concrete is $70 \mathrm{~mm}$ and $35 \mathrm{~mm}$, whereas for concrete with recycled aggregates they are $148 \mathrm{~mm}$ and $10 \mathrm{~mm}$ respectively. The minimum value is recorded in batch $\mathrm{B} 1$ (with $10 \% \mathrm{RCA}$ ) and the maximum value is observed in batch B4 (with $40 \%$ RCA), showing that the increase in the dose of recycled aggregates gave rise to water penetration.

\section{TABLE III. WATER PENETRATION TEST RESULTS}

\begin{tabular}{|c|c|c|c|c|c|c|c|c|}
\hline \multirow{2}{*}{ Batch } & \multirow{2}{*}{ Sample No } & \multirow{2}{*}{ RCA (\%) } & \multicolumn{6}{|c|}{ Water penetration depth (mm) } \\
\hline & & & 1 & 2 & 3 & 4 & 5 & 6 \\
\hline \multirow{4}{*}{ B1 } & 1 & \multirow{4}{*}{0} & 60 & 65 & 60 & 60 & 50 & 50 \\
\hline & 2 & & 40 & 55 & 52 & 56 & 35 & 50 \\
\hline & 3 & & 50 & 52 & 38 & 48 & 50 & 40 \\
\hline & 4 & & 42 & 48 & 49 & 70 & 52 & 60 \\
\hline \multirow{4}{*}{ B2 } & 1 & \multirow{4}{*}{10} & 30 & 40 & 70 & 20 & 20 & 10 \\
\hline & 2 & & 56 & 55 & 70 & 42 & 35 & 56 \\
\hline & 3 & & 60 & 53 & 65 & 40 & 50 & 50 \\
\hline & 4 & & 62 & 62 & 45 & 60 & 60 & 74 \\
\hline \multirow{4}{*}{ B3 } & 1 & \multirow{4}{*}{20} & 60 & 48 & 55 & 78 & 48 & 45 \\
\hline & 2 & & 44 & 54 & 52 & 45 & 52 & 70 \\
\hline & 3 & & 33 & 40 & 55 & 50 & 45 & 50 \\
\hline & 4 & & 45 & 45 & 55 & 35 & 50 & 52 \\
\hline \multirow{4}{*}{ B4 } & 1 & \multirow{4}{*}{30} & 110 & 65 & 70 & 55 & 70 & 100 \\
\hline & 2 & & 95 & 64 & 60 & 50 & 70 & 110 \\
\hline & 3 & & 70 & 70 & 55 & 65 & 65 & 75 \\
\hline & 4 & & 100 & 100 & 74 & 70 & 70 & 66 \\
\hline \multirow{4}{*}{ B5 } & 1 & \multirow{4}{*}{40} & 145 & 80 & 70 & 75 & 90 & 148 \\
\hline & 2 & & 60 & 40 & 75 & 55 & 62 & 60 \\
\hline & 3 & & 65 & 140 & 70 & 75 & 70 & 68 \\
\hline & 4 & & 45 & 70 & 57 & 54 & 50 & 65 \\
\hline \multirow{4}{*}{ B6 } & 1 & \multirow{4}{*}{50} & 72 & 67 & 75 & 42 & 70 & 64 \\
\hline & 2 & & 130 & 88 & 50 & 70 & 50 & 128 \\
\hline & 3 & & 110 & 65 & 58 & 48 & 55 & 120 \\
\hline & 4 & & 98 & 50 & 90 & 60 & 106 & 100 \\
\hline \multirow{4}{*}{ B7 } & 1 & \multirow{4}{*}{60} & 135 & 110 & 78 & 72 & 110 & 90 \\
\hline & 2 & & 60 & 80 & 80 & 80 & 82 & 65 \\
\hline & 3 & & 130 & 100 & 80 & 120 & 80 & 140 \\
\hline & 4 & & 85 & 90 & 92 & 80 & 70 & 60 \\
\hline
\end{tabular}

TABLE IV. AVERAGE WATER PENETRATION DEPTH

\begin{tabular}{|c|c|c|c|c|c|}
\hline \multirow{2}{*}{ RCA (\%) } & \multicolumn{4}{|c|}{ Average water depth (mm) } & \multirow{2}{*}{ Average depth of batch (mm) } \\
\cline { 2 - 5 } & 1 & 2 & 3 & 4 & 51 \\
\hline $\mathbf{0}$ & 58 & 48 & 46 & 54 & 49 \\
\hline $\mathbf{1 0}$ & 32 & 52 & 53 & 61 & 50 \\
\hline $\mathbf{2 0}$ & 56 & 53 & 46 & 47 & 75 \\
\hline $\mathbf{3 0}$ & 78 & 75 & 67 & 80 & 75 \\
\hline $\mathbf{4 0}$ & 101 & 59 & 81 & 57 & 78 \\
\hline $\mathbf{5 0}$ & 65 & 86 & 76 & 84 & 90 \\
\hline $\mathbf{6 0}$ & 99 & 75 & 75 & 80 & \multicolumn{2}{|c|}{} \\
\hline
\end{tabular}

The average water penetration in conventional concrete is equal to $51 \mathrm{~mm}$. An increasing trend in the water penetration depth with increase in quantity of recycled aggregates is 
observed. Water penetration depth of concrete with recycled aggregates is also compared with conventional concrete's in Figure 5. It may be observed that $30 \%$ and $40 \%$ replacement show identical values of penetration depths and very minor differences for $10 \%$ and $20 \%$ replacement of conventional coarse aggregates. The difference percentage of water penetration depth of concrete with recycled aggregates with respect to conventional concrete is shown in Figure 6.

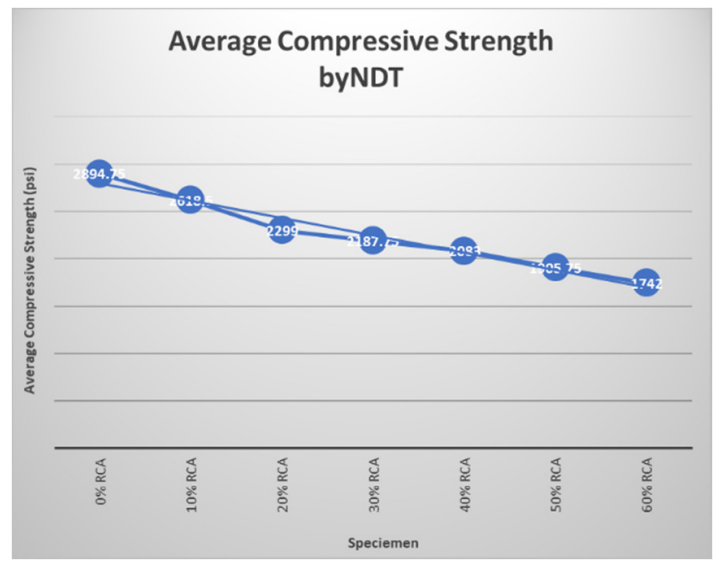

Fig. 4. Average compressive strength

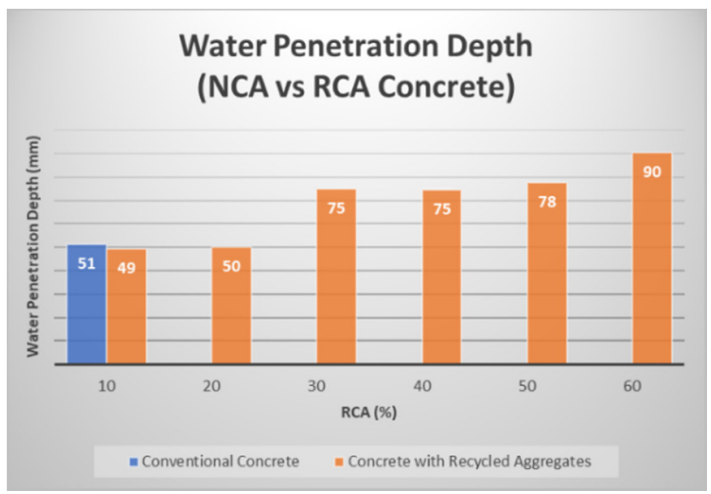

Fig. 5. Average water penetration depth.

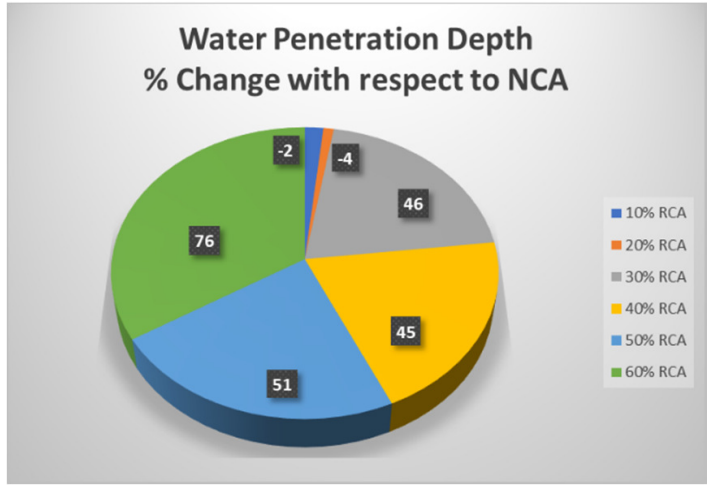

Fig. 6. The percentage change in penetration depth.

It may be observed that $60 \%$ dosage of recycled aggregates results in $76 \%$ higher values than conventional concrete. Lower dosages, i.e. $10 \%$ and $20 \%$, show better performance of the proposed concrete with $1 \%$ and $2 \%$ lesser water penetration than the conventional concrete. It may also be noted that the obtained results are better than the results published by authors in [30] for concrete made with brick aggregates. They reported water penetration depth in the range of $225 \%-550 \%$ in comparison with conventional concrete. The comparison of the acquired results with those published in [31] show that for $20 \%$ replacement, the water penetration level results of this work are $29 \%$ less whereas for $60 \%$ replacement are about $12 \%$ more. Although the internal structure of the specimens was observed good and similar to that of conventional concrete, yet an increase in water penetration is observed, probably due to the old mortar attached to the recycled aggregates which absorbs more water. Also, during the compaction of the specimens or even under the sustained pressure of water, this mortar disintegrates resulting in some voids witch get filled when the concrete comes in contact of water.

\section{CONCLUSION}

In this research work, the results of laboratory investigations on the evaluation of water penetration depth in concrete made with recycled aggregates are presented. Conventional concrete allowed the water to penetrate up to an average depth of $51 \mathrm{~mm}$. Recycled aggregate concrete exhibited a slight resistance up to $2 \%$ with $10 \%$ and $20 \%$ replacement of conventional aggregates, but an increase up to $76 \%$ with increase in dosage of the recycled aggregates. The increased water penetration is mainly attributed to the old mortar attached to the recycled aggregates. Based on the findings of compressive strength and water penetration tests, it is concluded that $20 \%$ replacement of conventional coarse aggregates is in good agreement with conventional concrete's behavior. Replacement beyond this limit would require proper treatment of the concrete's surface exposed to water.

\section{REFERENCES}

[1] B. A. Memon, "Recent Development on Use of Demolished Concrete as Coarse Aggregates," International Journal of Emerging Technology and Innovative Engineering, vol. 2, no. 1, pp. 1-11, Jan. 2016.

[2] K. McNeil and T. H.-K. Kang, "Recycled Concrete Aggregates: A Review," International Journal of Concrete Structures and Materials, vol. 7, no. 1, pp. 61-69, Mar. 2013, https://doi.org/10.1007/s40069-0130032-5.

[3] Y. Zhuge, "The performance of recycled and quarry aggregates and their effect on permeable concrete," in Proceedings of Concrete 2013, Sydney, Australia, Oct. 2013.

[4] A. Cheng, H.-M. Hsu, S.-J. Chao, and K.-L. Lin, "Experimental study on properties of pervious concrete made with recycled aggregate," International Journal of Pavement Research and Technology, vol. 4, no. 2, pp. 104-110, Mar. 2011.

[5] V. Ghorpade and H. Rao, "Strength and permeability characteristics of Fibre reinforced recycled aggregate concrete with different fibres," Nature Environment and Pollution Technology, vol. 9, no. 1, pp. 179188, Mar. 2010.

[6] 6 V. G. Ghorpade, H. S. Rao, "Strength and Permeability Characteristics of Fiber Reinforced High Performance Concrete with Recycled Aggregates", Asian Journal of Civil Engineering, Vol. 13, No. $1,2012$.

[7] G. F. Peng, Q. B. Liu, Z. B. Guo, Q. X. Hou, S. Q. Cao, and J. F. Zhang, "Mechanical Properties and Permeability of Recycled Aggregate Concrete at Low Water/Binder Ratio," Key Engineering Materials, vol. 477, pp. 16-22, Apr. 2011, https://doi.org/10.4028/www.scientific.net/ KEM.477.16. 
[8] L. Zong, Z. Fei, and S. Zhang, "Permeability of recycled aggregate concrete containing fly ash and clay brick waste," Journal of Cleaner Production, vol. 70, pp. 175-182, May 2014, https://doi.org/10.1016/ j.jclepro.2014.02.040.

[9] L. A. Pereira-de-Oliveira, M. C. S. Nepomuceno, J. P. Castro-Gomes, and M. F. C. Vila, "Permeability properties of self-compacting concrete with coarse recycled aggregates," Construction and Building Materials, vol. 51, pp. 113-120, Jan. 2014, https://doi.org/10.1016/j.conbuildmat. 2013.10.061.

[10] S. Ismail and M. Ramli, "Effects of Adding Fibre on Strength and Permeability of Recycled Aggregate Concrete Containing Treated Coarse RCA," International Journal of Civil and Environmental Engineering, vol. 8, no. 8, pp. 918-924, Aug. 2014.

[11] P. Wu, X. Wang, T. Huang, and W. Zhang, "Permeability and Prediction of Free Chloride Ion in Recycled Aggregate Concrete with Fly Ash," International Journal of Electrochemical Science, vol. 9, pp. 35133535, Apr. 2014

[12] F. Özalp, H. D. Yılmaz, M. Kara, Ö. Kaya, and A. Şahin, "Effects of recycled aggregates from construction and demolition wastes on mechanical and permeability properties of paving stone, kerb and concrete pipes," Construction and Building Materials, vol. 110, pp. 17 23, May 2016, https://doi.org/10.1016/j.conbuildmat.2016.01.030.

[13] H. Wang, X. Sun, J. Wang, and P. J. M. Monteiro, "Permeability of Concrete with Recycled Concrete Aggregate and Pozzolanic Materials under Stress," Materials, vol. 9, no. 4, p. 252, Apr. 2016, https://doi.org/ 10.3390/ma9040252.

[14] K. Kapoor, S. P. Singh, and B. Singh, "Permeability of self-compacting concrete made with recycled concrete aggregates and metakaolin," Journal of Sustainable Cement-Based Materials, vol. 6, no. 5, pp. 293313, Sep. 2017, https://doi.org/10.1080/21650373.2017.1280426.

[15] S. Kamaruddin, "Self-Compacting Concrete with incorporation of Recycled Concrete Aggregates," International Journal of Integrated Engineering, vol. 11, no. 9, pp. 164-173, Dec. 2019.

[16] M. T. Lakhiar, N. Mohamad, A. A. Jhatial, S. Sohu, and M. Oad, "Mechanical Properties of Concrete Containing River Indus Sand and Recyclable Concrete Aggregate," Civil Engineering Journal, vol. 4, no. 8, pp. 1869-1876-1876, Aug. 2018, https://doi.org/10.28991/cej03091121 .

[17] A. R. Sandhu, M. T. Lakhiar, A. A. Jhatial, H. Karira, and Q. B. Jamali, "Effect of River Indus Sand and Recycled Concrete Aggregates as Fine and Coarse Replacement on Properties of Concrete," Engineering, Technology \& Applied Science Research, vol. 9, no. 1, pp. 3832-3835, Feb. 2019, https://doi.org/10.48084/etasr.2558.

[18] W. Z. Taffese, "Suitability Investigation of Recycled Concrete Aggregates for Concrete Production: An Experimental Case Study," Advances in Civil Engineering, vol. 2018, Sep. 2018, Art. no. 8368351, https://doi.org/10.1155/2018/8368351.

[19] J. Thomas, N. N. Thaickavil, and P. M. Wilson, "Strength and durability of concrete containing recycled concrete aggregates," Journal of Building Engineering, vol. 19, pp. 349-365, Sep. 2018, https://doi.org/10.1016/j.jobe.2018.05.007.

[20] S. Kaliannan, S. Nagapan, A. H. Abdullah, S. Sohu, and A. A. Jhatial, "Determining Root Cause of Construction Waste Generation: A Global Context," Civil Engineering Journal, vol. 4, no. 11, pp. 2539-25472547, Nov. 2018, https://doi.org/10.28991/cej-03091179.

[21] M. Oad, A. H. Buller, B. A. Memon, N. A. Memon, and S. Sohu, "Long Term Impact in Reinforced Recycled Concrete Beams Under 9-Month Loading," Engineering, Technology \& Applied Science Research, vol. 9, no. 3, pp. 4140-4143, Jun. 2019, https://doi.org/10.48084/etasr.2697.

[22] M. Oad, B. A. Memon, A. H. Buller, and N. A. Memon, "Flexural Behavior of RC Beams Made with Recycled Aggregates Under 12Month Long Term Loading," Engineering, Technology \& Applied Science Research, vol. 9, no. 5, pp. 4631-4635, Oct. 2019, https://doi.org/10.48084/etasr.3013.

[23] A. H. Buller, M. Oad, and B. A. Memon, "Flexural Behavior of Reinforced RAC Beams Exposed to $1000^{\circ} \mathrm{C}$ Fire for 18 Hours," Engineering, Technology \& Applied Science Research, vol. 9, no. 3, pp. 4225-4229, Jun. 2019, https://doi.org/10.48084/etasr.2733.
[24] A. H. Buller, M. Oad, B. A. Memon, and S. Sohu, "24-hour Fire Produced Effect on Reinforced Recycled Aggregates Concrete Beams," Engineering, Technology \& Applied Science Research, vol. 9, no. 3, pp. 4213-4217, Jun. 2019, https://doi.org/10.48084/etasr.2764.

[25] L. Evangelista and J. Brito, "Permeability properties of fine recycled aggregate concrete," presented at the 4th International Conference on Sustainable Solid Waste Management., Limassol, Cyprus, Jun. 2016.

[26] W. Kubissa, R. Jaskulski, and M. Brodňan, "Influence of SCM on the Permeability of Concrete with Recycled Aggregate," Periodica Polytechnica Civil Engineering, vol. 60, no. 4, pp. 583-590, Oct. 2016, https://doi.org/10.3311/PPci.8614.

[27] J.-C. Souche, P. Devillers, M. Salgues, and E. Garcia Diaz, "Influence of recycled coarse aggregates on permeability of fresh concrete," Cement and Concrete Composites, vol. 83, pp. 394-404, Oct. 2017, https://doi.org/10.1016/j.cemconcomp.2017.08.002.

[28] M. Gruszczyński and M. Lenart, "Liquid Penetration Depth and Strength of Concretes Modified with Polymer Admixtures Under the Action of Crude-Oil Products," Materials, vol. 12, no. 23, Nov. 2019, https://doi.org/10.3390/ma12233900.

[29] Standard Test Method for Density, Absorption and Voids in hardened Concrete, ASTM C642, ASTM, West Conshohocken, PA, USA, 2013.

[30] S. I. Ahmad and M. A. Hossain, "Water Permeability Characteristics of Normal Strength Concrete Made from Crushed Clay Bricks as Coarse Aggregate," Advances in Materials Science and Engineering, vol. 2017, Nov. 2017, Art. no. 7279138, https://doi.org/10.1155/2017/7279138.

[31] S. H. Adnan, Lee, Y. L. Lee, I. Abdul Rahman, H. Mohd, and M. Wimala, "Water Permeability of Recycled Aggregate Concrete," presented at the Technology and Innovation for Sustainable Development Conference, Khon Kaen, Thailand, Jan. 2008. 